\title{
Desain Sliding Mode Tracking Control untuk WMR Menggunakan Matlab
}

\author{
Ryan Laksmana Singgeta \\ Prodi Teknik Elektro; Fakultas Teknik \\ Universitas Katolik De La Salle; Kairagi I Kombos Manado, No. Telp(0431)871957 \\ e-mail: rsinggeta@unikadelasalle.ac.id
}

\begin{abstract}
Abstrak-Mobile robot adalah salah satu jenis robot yang menggunakan aktuator/penggerak untuk mengubah keadaan serta posisi dari satu titik ke titik yang lain. Wheeled mobile robots (WMR) atau roda robot biasanya dikontrol dan dikendalikan agar bisa bergerak dan berpindah posisi sesuai yang ditentukan. Pengendalian WMR sering digunakan dalam otomasi pada proses industri serta di bidang lain seperti pertanian. Untuk mendapatkan performans WMR yang baik maka perlu merancang dan mendesain kontrol yang tepat. Dalam paper ini sliding mode tracking control di desain untuk mengendalikan wheeled mobile robots yang disimulasikannya menggunnakan Matlab. Mobile robot merupakan non-holonomic systems. Penelitian ini telah banyak dilakukan pada masalah tracking kontrol pada WMR. Skema kinematic tracking kontrol tidak mempertimbangkan dinamika atau kelembaman (inersia) dari mobile robot. Adapun metode penelitian yang dilakukan adalah pertama, disajikan model kinematik dari empat jenis roda yang umum seperti fixed, centered orientable, castor and Swedish. Mobile robot pada paper ini dianalisa dengan kajian kinematik. Kedua, mendesain sebuah sliding mode tracking control untuk menemukan target sebagai lintasan yang telah ditentukan serta untuk mengurangi error pada posisi start. Dengan sliding mode control yang telah di desain, dapat menunjukan hasil respon yang baik, dimana WMR dapat bergerak pada lintasan menuju ke titik akhir/target yang telah ditentukan.
\end{abstract}

Kata Kunci-Sliding mode control, wheeled mobile robot, kinematic tracking control.

\section{PENDAHULUAN}

$\mathrm{D}$ alam beberapa tahun terakhir, banyak peneliti yang tertarik dalam area mobile robotics dan kontrol. Secara umum, jenis robot dapat dibedakan dalam 4 kategori, yaitu : mobile robot, non mobile robot, kombinasi mobile robot dan non mobile robot, dan humanoid robot [1]. Mobile dapat diartikan bergerak, jadi mobile robot adalah suatu robot yang bisa memindahkan dirinya dari satu tempat ke tempat lain dengan memanfaatkan aktuator. Jenis robot ini dapat membantu manusia dalam melakukan otomasi dalam transportasi, platform bergerak untuk robot industri , eksplorasi tanpa awak, dan lain - lain. Mobile robot ini merupakan robot yang cukup populer dalam dunia penelitian robotika. Salah satu penelitian pada mobile robot adalah terletak pada Wheeled mobile robot (WMR). WMR adalah robot beroda yang mampu melakukan gerak otonom tanpa dikemudi atau dikendalikan oleh manusia melainkan suatu komputer, mikrokontroller dan sejenisnya. WMR dikendalikan agar bisa bergerak sesuai dengan lintasan yang ditentukan dengan baik dan tepat. Posisi yang diinginkan dapat ditentukan sendiri dengan menggunakan metode trial-error, namun metode tersebut tidak fleksibel dikarenakan jika hendak merubah pergerakan robot, membutuhkan waktu yang lebih lama. Masalah yang lain adalah posisi-posisi tersebut harus ditanamkan pada robot sehingga akan banyak memakan memori. Beberapa penelitian telah mengembangkan sebuah control WMR berdasarkan metode geometris. Metode tersebut terdiri dari penerapan sinyal kontrol yang dirancang dan didesain agar WMR mengikuti kurva yang menghubungkan posisi sebenarnya dengan posisi sasaran pada lintasan referensi. Pada paper ini penulis merancang dan mendesain sebuah controller yang dapat mengendalikan pergerakan robot di lintasan yang ditentukan secara otomatis. Controller tersebut adalah sliding mode tracking control. Dibandingkan dengan pendekatan yang diperkenalkan sebelumnya, sliding mode control (SMC) memiliki banyak kelebihan untuk pelacakan lintasan mobile robot seperti respon yang cepat, transien yang baik dan robustness terhadap ketidakpastian sistem dan gangguan eksternal. Sliding Mode Controller $(S M C)$ merupakan sebuah kendali umpan balik pensaklaran berkecepatan tinggi (high speed switching feedback control) yang efektif dan kokoh dalam mengendalikan sistem linear maupun nonlinear [9]. Oleh karena itu, SMC sangat atraktif dalam karakteristik nonlinear dan uncertainty [3,4]. Pada paper ini, ada dua parameter sliding surfaces yang dipilih yaitu hal kesalahan pelacakan (tracking error) posisi dan arah depan (forward direction). Hasil dari grafik, terlihat bahwa $S M C$ yang telah didesain pada WMR dapat menunjukan performa yang baik dengan error yang kecil.

\section{TINJAUAN PUSTAKA}

Robot berasal dari bahasa Cekoslowakia. Kata robot berasal dari kosakata "Robota" yang berarti "kerja cepat". Istilah ini muncul pada tahun 1920 oleh seorang pengarang sandiwara bernama Karel Capec [1]. Dengan karyanya berjudul "Rossum's Universal Robot" yang artinya Robot Dunia milik Rossum. Ada beberapa fungsi robot, sehingga manusia memerlukan kehadirannya yaitu:

1. Peningkatan produksi, akurasi dan daya tahan. Robot ini banyak digunakan di bidang industri.

2. Robot digunakan untuk tugas-tugas yang berbahaya, kotor dan beresiko.

3. Banyak robot yang digunakan untuk menarik pelajar belajar teknologi.

4. Robot dirancang agar bisa menolong manusia. Seperti di rumah untuk membersihkan rumah di rumah sakit untuk menghantar makanan, membantu operasi, dan lain - lain. 
Jenis robot dapat dibedakan dalam 4 kategori yaitu : mobile robot, non mobile robot, kombinasi mobile robot dan non mobile robot, dan humanoid robot.

\section{A. Mobile Robot}

Mobile dapat diartikan bergerak yang dapat memindahkan dirinya dari satu tempat ke tempat lain. Robot ini merupakan robot yang paling populer dalam dunia penelitian robotika. Dari segi manfaat, robot ini diharapkan dapat membantu manusia dalam melakukan otomasi dalam transportasi, platform bergerak untuk robot industri, eksplorasi tanpa awak,

dan sebagainya. Contoh dari mobile robot dapat dilihat pada gambar 1. Komponen utamanya terdiri dari 4 bagian, yaitu: Sensor, Aktuator, dan Controller.

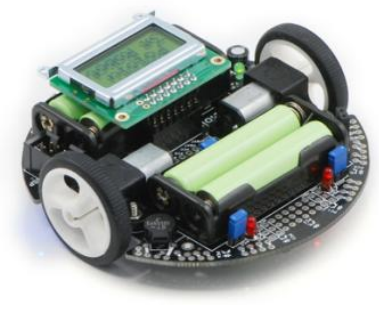

Gambar. 1. Mobile Robot.

Struktur robot sebagian besar dibangun berdasarkan konstruksi mekanik. Robot yang memiliki kemampuan navigasi dan manipulasi secara relatif memiliki konstruksi mekanik yang lebih rumit dibandingkan dengan yang berkemampuan navigasi saja, seperti mobile robot tanpa tangan yang hanya memiliki roda penggerak. Namun demikian robot berjalan (walking robot) seperti misalnya biped (dua kaki) dapat memiliki konstruksi mekanik yang rumit dibandingkan dengan robot tangan planar. Hal yang mendasar yang harus di perhatikan dalam mendisain mekanik robot adalah perhitungan kebutuhan torsi untuk menggerakkan sendi atau roda. Motor sebagai penggerak utama (prime - mover) yang paling sering dipakai umumnya akan bekerja optimal (torsi dan kecepatan yang paling ideal) pada putaran yang relatif tinggi yang hal ini tidak sesuai bila porosnya dihubungkan langsung ke sendi gerak atau roda. Sebab kebanyakan gerakan yang diperlukan pada sisi anggota badan robot adalah relatif pelan namun bertenaga. Untuk itu diperlukan transmisi daya motor (atau aktuaktor secara umum) secara tepat.

\section{B. Sistem Kontrol Robotika}

Sistem kontrol adalah suatu proses pengaturan/ pengendalian terhadap satu atau beberapa besaran (variabel, parameter) sehingga berada pada suatu harga atau dalam rangkuman harga (range) tertentu [8]. Dalam istilah lain disebut juga teknik pengaturan, sistem pengendalian atau sistem pengontrolan. Ditinjau dari segi peralatan dan Instrument yang digunakan, sistem kendali terdiri dari berbagai susunan komponen fisik yang digunakan untuk mengarahkan aliran energi ke suatu mesin atau proses agar dapat menghasilkan prestasi yang diinginkan. Tujuan utama dari suatu sistem kontrol adalah untuk mendapatkan optimasi, dalam hal ini dapat diperoleh berdasarkan fungsi dari sistem kendali itu sendiri, yaitu pengukuran (measurement), membandingkan (comparison), pencatatan dan perhitungan (computation) dan perbaikan (correction). sehingga memudahkan pengoperasian, peningkatan efisiensi dan kualitas kerja suatu sistem, meniadakan pekerjaan rutin yang harus dilakukan oleh manusia, serta masih banyak lagi pengaruh yang disebabkan oleh perkembangan dari pengendalian otomatik. Sistem kontrol robotik pada dasarnya terbagi menjadi dua kelompok, yaitu sistem kontrol loop terbuka (open loop) dan loop tertutup (close loop).

Kontrol loop terbuka atau umpan maju (feed foward control) dapat dinyatakan sebagai sistem kontrol yang outputnya tidak diperhitungkan ulang oleh kontroler (gambar 2). Keadaan apakah robot benar - benar telah mencapai target seperti yang dikehendaki sesuai referensi, adalah tidak dapat mempengaruhi kerja kontroler. Kontrol ini sesuai untuk sistem operasi robot yang memiliki aktuaktor yang beroprasi berdasarkan logika berbasis konfigurasi langkah sesuai urutan, misalnya motor stepper. Stepper motor tidak perlu dipasangi sensor pada porosnya untuk mengetahui posisi akhir. Jika dalam keadaan berfungsi baik dan tidak ada masalah beban lebih maka stepper motor akan berputar sesuai dengan perintah kontroler dan mencapai posisi target dengan cepat.

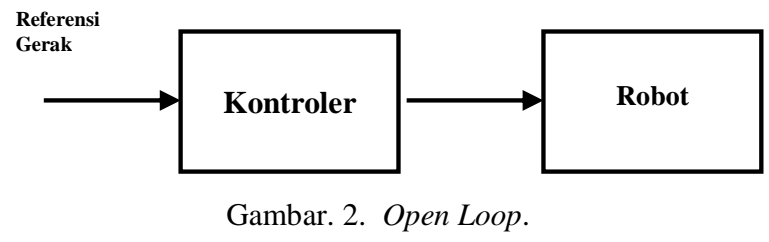

Pada gambar 3, jika gerak hasil gerak aktual telah sama dengan referensi maka input kontroler akan nol. Artinya kontroler tidak lagi memberikan sinyal aktusi kepada robot karena target akhir perintah gerak telah diperoleh. Makin kecil error maka makin kecil pula sinyal pengemudian kontroler terhadap robot, sampai akhirnya mencapai kondisi tenang (steady state). Referensi gerak dan gerak aktual dapat berupa posisi (biasanya didefinisikan melalui kedudukan ujung lengan terakhir / end of effector), kecepatan, akselerasi atau gabungan diantaranya.

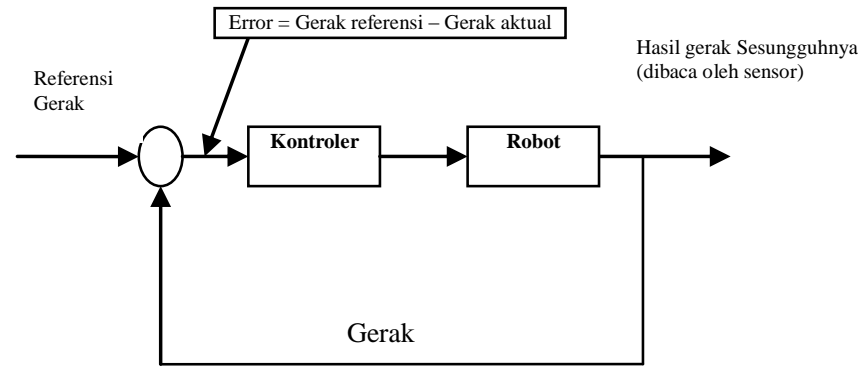

Gambar. 3. Close Loop

PID Controller merupakan sistem kontrol close loop yang banyak digunakan. Sistem ini mudah digabungkan dengan metoda pengaturan yang lain seperti Fuzzy dan Robust. 
Sehingga akan menjadi suatu sistem pengatur yang semakin baik. Kontrol PID menggabungkan kontrol P, I dan D maka masing - masing kelebihannya dapat disatukan guna mendapatkan kontrol yang ideal. Masing-masing memiliki parameter tertentu yang harus diset untuk dapat beroperasi dengan baik, yang disebut sebagai konstanta. Setiap jenis, memiliki kelebihan dan kekurangan masing-masing, hal ini dapat dilihat pada tabel di bawah ini: Sistem kontrol PID bekerja baik untuk sistem yang cenderung linier dalam fungsi waktu.

Suatu proses fisik yang berlangsung di alam ini bekerja secara kompleks dan nonlinear sehingga cukup sering menyulitkan dalam hal identifikasi sistem tersebut. Oleh sebab itulah diperlukan intepretasi matematis dari proses fisika yang akan dikendalikan untuk mempermudah perancangan pengendali, yang dinamakan pemodelan atau identifikasi Kenyataan ini seringkali menghasilkan ketidaktepatan dalam hal pemodelan, sehingga menghasilkan kinerja sistem kendali yang tidak sesuai harapan. Ketidaktepatan dalam pemodelan ini secara umum disebabkan oleh dua hal :

1. Ketidakpastian dari plant (parameter-parameter dalam plant tidak diketahui)

2. Proses penyederhanaan dari dinamika sistem dengan tujuan untuk mempermudah perhitungan. Seringkali para perancang sistem kendali menggunakan berbagai asumsi serta mengabaikan beberapa hal yang lain meskipun hal tersebut menghasilkan pengaruh yang besar terhadap sistem.

Ketidaktepatan dalam pemodelan ini diklasifikasikan menjadi dua macam, yaitu :

1. Structured uncertainty (ketidakpastian yang terstruktur) terjadi akibat ketidaktepatan pada penentuan nilai parameter-parameter pada sistem.

2. Unstructured uncertainty (ketidakpastian yang tidak terstruktur) terjadi akibat ketidaktahuan tentang bentuk sistem itu sendiri, bahkan hingga pada tingkat orde sistem

Kedua masalah di atas dipengaruhi oleh ketidaklinearan sistem, sehingga diperlukan pengetahuan khusus untuk menangani hal tersebut. Terdapat dua metode yang umum digunakan untuk mengatasi masalah ketidaktepatan dalam pemodelan dalam sistem kendali yaitu [11] :

\section{Robust Control System}

Sistem ini seperti pada sistem kendali kalang tertutup pada umumnya, dnamun ada bagian tambahan untuk mengatasi masalah ketidaktepatan pemodelan. Sistem kendali yang Robust (kokoh) haruslah bisa menghasilkan kinerja yang baik untuk berbagai model dari plant dengan interval nilai tertentu.

\section{Adaptive Control}

Sistem Kendali Adaptif memiliki bagian tambahan yang selalu diupdate/diperbaharui nilainya selama proses berlangsung secara online berdasar nilai pengukuran pada kinerja sistem. Sistem ini bisa diaplikasikan untuk semua model plant, bahkan yang tidak diketahui struktur maupun parameternya. Salah satu contoh metode pengendalian berbasis Robust Control adalah yang disebut dengan Sliding Mode Control.

\section{Kinematic Control}

Perkembangan penelitian di bidang robotika dapat diketahui dengan mencermati aplikasinya di dunia industri atau produk kegiatan penelitian skala laboratorium dan group-group penelitian yang tersebar di berbagai institusi pendidikan dan penelitian di negara-negara maju. Fokus penelitian dititik beratkan pada kinematik dan dinamik pada WMR. Dalam hal ini seringkali pembahasan yang mendalam secara matematik sangat diperlukan. Pengendalian sistem non-holonomic telah banyak dipelajari mengingat mekanika klasik mengacu pada sistem kinematika dan model dinamis. Salah satu metode awal pengendalian WMR adalah pengendalian kinematika. Diasumsikan bahwa massa dan inersia mobile robot dan rodanya dapat diabaikan. Biasanya, input kontrol untuk model kontrol kinematika adalah kecepatan. Teknik kontrol lainnya adalah model kontrol dinamis. Ini agak rumit karena melibatkan sejumlah parameter seperti massa, pusat gravitasi, gaya, torsi, kecepatan, percepatan dan momen massa inersia. dinamika robot sangat menjanjikan dalam perolehan kontribusi keilmuannya.

Tujuan utama kajian dinamik tersebut adalah untuk mendapatkan desain kontrol yang lasak (robust) yang mampu meredam gangguan dengan baik. Kemudian sejumlah peneliti telah meneliti penerapan kontrol dinamik yang juga

menggabungkan elemen kontrol adaptif, kontrol cerdas, kontrol yang kuat dan sebagainya. Model kinematis mobile robot roda paralel gagal memenuhi kondisi yang dibutuhkan brockett untuk stabilisasi umpan balik [2,3]. Ini menyiratkan bahwa tidak ada umpan balik keadaan statis yang mulus atau bahkan kontinu yang membuat sistem loop tertutup stabil secara asimtotik. WMR mempunyai banyak tipe/jenis. WMR tipe 1 dibangun tanpa roda tetap atau orientable, yaitu dengan roda Swedish atau castor biasa disebut omnidirectional. WMR tipe 2 memiliki satu roda tetap independen dan roda lain yang mungkin omnidirectional (Swedish atau castor). WMR tipe 3 memiliki satu roda orientasi independen dan roda omnidirectional lainnya. Contohnya adalah WMR syncrodrive. WMR tipe 4 memiliki satu roda penggerak independen dan roda tetap independen lainnya. Contoh jenis ini adalah $W M R$ roda tiga, sepeda $W M R$, dan mobil seperti $W M R$. WMR tipe 5 dicirikan oleh dua roda orientable independen. Perhatikan bahwa, derajat mobilitas mewakili jumlah derajat kebebasan yang dapat digunakan seketika, tanpa reorientasi roda yang orientable. Dengan demikian, juga didefinisikan tingkat kemampuan manuver $\mathrm{g}$ sebagai jumlah derajat mobilitas dan steeribility, dan mewakili tingkat kebebasan total, dengan reorientasi roda orientables. Oleh karena itu, jenis $W M R$ tipe 1,3 , dan 5 memiliki kemampuan manuver penuh $(\mathrm{g}=3)$ dan $W M R$ tipe 2 dan 4 memiliki kemampuan manuver yang terbatas $(\mathrm{g}=2)$. [5] 


\section{METODE PENELITIAN}

\section{A. Sliding Mode Control}

Sliding Mode Control merupakan salah satu metode pengendalian sistem melalui aplikasi dari kendali pensaklaran (switching) berfrekuensi tinggi. Sliding mode control memiliki sifat kokoh terhadap gangguan maupun perubahan parameter [10]. Kekurangan dari penggunaan kontroler $S M C$ adalah adanya fenomena chattering yang dapat mengganggu stabilitas dari sistem kendali. Sliding Mode Control diharapkan dapat mengatur posisi depan robot dan dapat melacak dan mengikuti target sesuai referensi. Namun, penggunaan kontroler ini akan mengakibatkan terjadinya chattering yang kurang baik untuk respon sistem sehingga keberadaannya perlu direduksi.

Kerangka robot didefinisikan sebagai titik tengah pada poros antara roda. Pusat massa robot diasumsikan berada pada sumbu simetri, pada jarak dari pusat seperti yang ditunjukkan pada Gambar 4. Gerakan robot diasumsi berikut.

1. Gerakan hanya pada bidang horizontal

2. Kontak titik yang melibatkan roda dan ground

3. Roda tidak berubah bentuk

4. Murni bergulir

5. Tidak tergelincir dan meluncur

6. Tidak ada gesekan tentang titik kontak

7. Roda dengan rangka yang kaku (chassis)

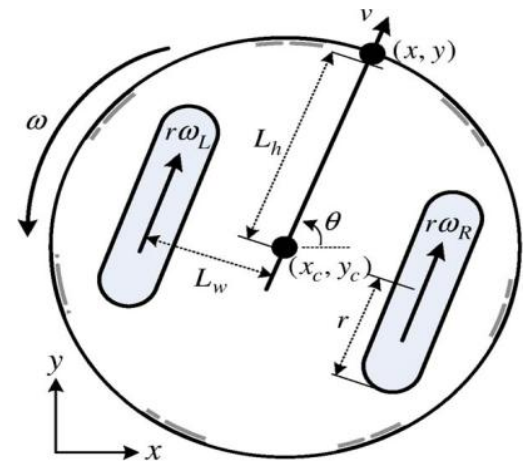

Gambar 4. Wheeled Mobile Robot

Persamaan kinematik untuk robot itu digambarkan sebagai berikut:

$$
\left[\begin{array}{l}
x_{i}(t) \\
y_{i}(t)
\end{array}\right]=\left[\begin{array}{l}
x_{c i}(t) \\
y_{c i}(t)
\end{array}\right]+L_{h}\left[\begin{array}{c}
\cos \theta_{i}(t) \\
\sin \theta_{i}(t)
\end{array}\right]
$$

Dimana $L h$ adalah panjang antara posisi tengah dan kepala, $(x c i(t)$, yci (t)) adalah posisi tengah, dan $\theta i(t)$ adalah sudut rotasi. Membedakan [6] berkenaan dengan waktu, persamaan posisi kepala untuk robot ith dapat ditentukan sebagai berikut: [7] :

$$
\left[\begin{array}{c}
\dot{x} i(t) \\
\dot{y} i(t)
\end{array}\right]=\left[\begin{array}{cc}
\cos \theta i(t)-L h \sin \theta i(t) \\
\sin \theta i(t) & L h \cos \theta i(t)
\end{array}\right]\left[\begin{array}{c}
v i(t) \\
\omega i(t)
\end{array}\right]
$$

Bentuk alternatif lain untuk model kinematiknya adalah diperoleh sebagai,

$$
\left[\begin{array}{c}
x \dot{c} \\
y \dot{c} \\
\theta \dot{c}
\end{array}\right]=\left[\begin{array}{cc}
\cos \theta & 0 \\
\sin \theta & 0 \\
0 & 1
\end{array}\right]\left[\begin{array}{c}
v \\
\omega
\end{array}\right]
$$

\section{B. Desain Sliding Mode Control}

Pada paper ini, ada dua parameter sliding surfaces yang dipilih yaitu hal kesalahan pelacakan (tracking error) posisi dan arah depan (forward direction). Sliding Mode Control diharapkan dapat mengendalikan posisi depan robot dengan lintasan agar stabil sesuai referensi/target. Penggunaan kontroler ini akan mengakibatkan terjadinya chattering yang kurang baik untuk respon sistem sehingga keberadaannya perlu direduksi. Pada tahap ini penulis menyelidiki variable struture control (VSC) sebagai kontrol umpan balik switched pada sliding mode. Gain di setiap jalur umpan balik switch di antara dua nilai bergantung pada nilai state di setiap situasi/kondisi. Tujuan dari switching control law adalah untuk mengendalikan nonlinear plant's state trajectory ke area/lintasan yang ditentukan sebelumnya (yang dipilih pengguna) sekaligus untuk mempertahankan lintasan untuk waktu berikutnya.

Dalam bagian ini, penulis menggunakan metode $S M C$ untuk merancang pengendali pelacakan kinematik yang membiarkan kecepatan aktual WMR bertemu dengan kecepatan kontrol yang dihasilkan dari pengontrol kinematik. Hasil Perancangan controller ini disimulasikan menggunakan Matlab Perancangan sistem sliding mode controller secara garis besar dinyatakan dalam persamaan berikut.

$$
\left[\begin{array}{l}
v \\
\omega
\end{array}\right]=\left[\begin{array}{cc}
\cos \theta & \sin \theta \\
-\frac{1}{h} \sin \theta \frac{1}{h} \cos \theta
\end{array}\right]\left[\begin{array}{l}
u x \\
u y
\end{array}\right]
$$

Sliding surface dinyatakan sebagai berikut:

$$
\begin{aligned}
& s x=e x+c \int e x \\
& s y=e y+c \int e x
\end{aligned}
$$

Untuk Chattering avoidance seperti di bawah ini:

$$
\operatorname{sgn}(s) \approx \frac{s}{[s]+\varepsilon} s x^{2}
$$

Dimana ex adalah error $\mathrm{x}$, ey adalah error $\mathrm{y}$, dan c adalah konstanta postive.

Penulis menggunakan fungsi Lyapunov serperti berikut ini:

$$
V=\frac{1}{2} s x^{2}+\frac{1}{2} s y^{2}
$$




$$
\begin{aligned}
& \dot{V}=s x \dot{x}+s y s \dot{y} \\
& \dot{V}=s x(e \dot{x}+c e x)+s y(e \dot{y}+c e y) \\
& \dot{V}=s x(x \dot{h}-x \dot{d}+c e x)+s y(y \dot{h}-y d+c e y)
\end{aligned}
$$

Dengan menggunakan fungsi Lyapunov dalam menjabarkannya maka kontroler telah didapatkan dengan persamaan sebagai berikut

$$
\begin{gathered}
u x=x \dot{d}-c . e x-k \operatorname{sign}|x| \\
u y=y \dot{d}-c . e y-k \operatorname{sign}|y| \\
\dot{V}=-k|s x|-k|s y| \quad \dot{V} \leq 0
\end{gathered}
$$

Dimana k adalah bilangan konstan positif.

\section{HASIL DAN PEMBAHASAN}

Bab ini akan membahas simulasi dan analisis hasil pengujian dari pemodelan sistem sliding mode tracking control dengan menggunakan Matlab. Pengujian ini bertujuan untuk mengetahui performa sistem sliding mode controller terhadap pelacakan target dan posisi WMR. Adapun beberapa paramater yang ditentukan dan ditetapkan pada tahap pengujian yaitu lintasan garis lurus yang dihasilkan dari kecepatan sudut target yang diinginkan adalah dqxd $=0$, dqyd $=0$ dan nol. Posisi target WMR adalah [qxd qyd hr] $\mathrm{T}=\left[\begin{array}{ll}2 & 2\end{array}\right.$ 0] T. Untuk posisi awal $W M R$ yang aktual ditetapkan dengan [qx (0) qy (0) $\mathrm{hr}(0)] \mathrm{T}=\left[\begin{array}{lll}0,2 & 0 & 0\end{array}\right] \mathrm{T}$ dengan panjang body depan adalah 0,2 .

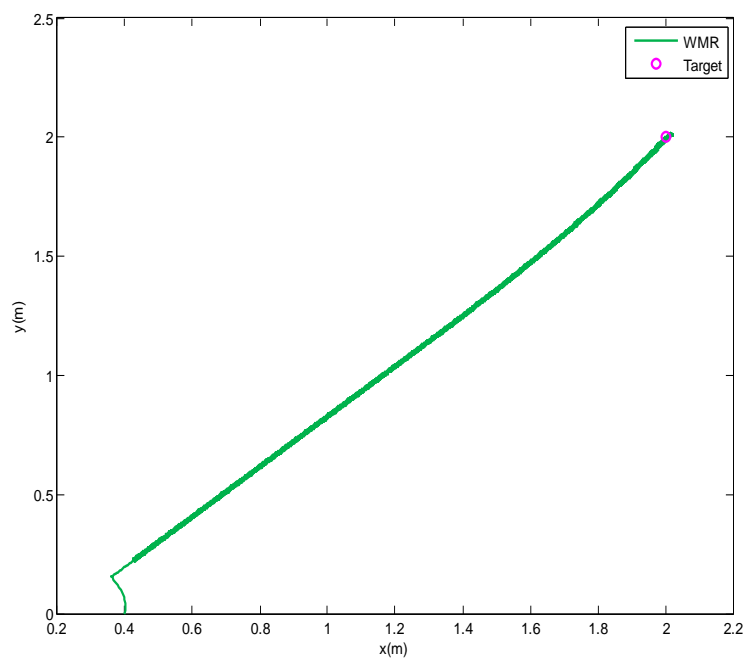

Gambar 5. Lintasan dari SMC

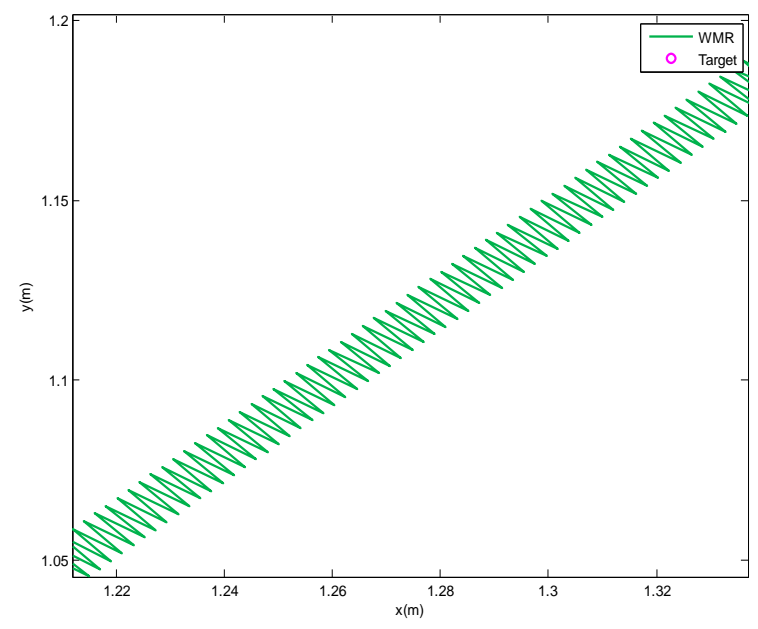

Gambar 6. Chattering of SMC

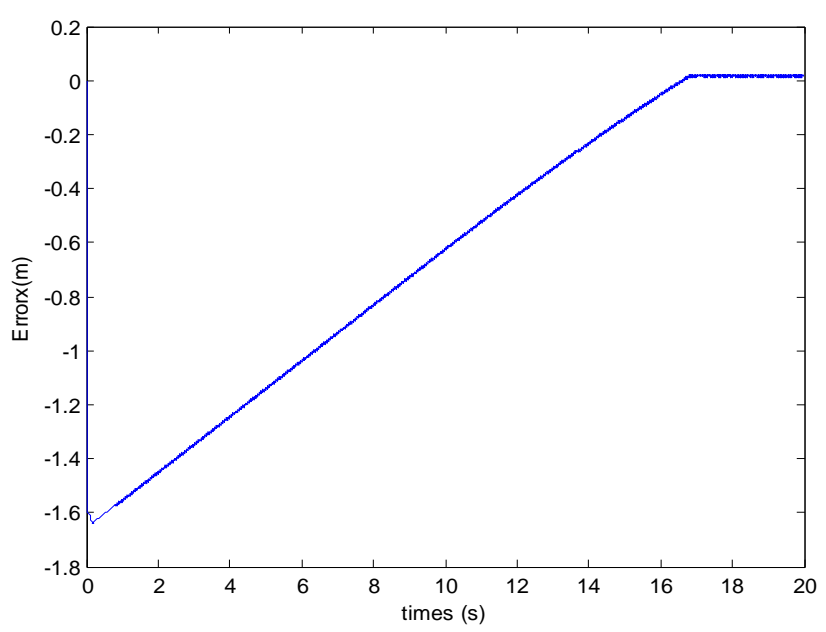

Gambar 7. Tracking Error pada koordinat X

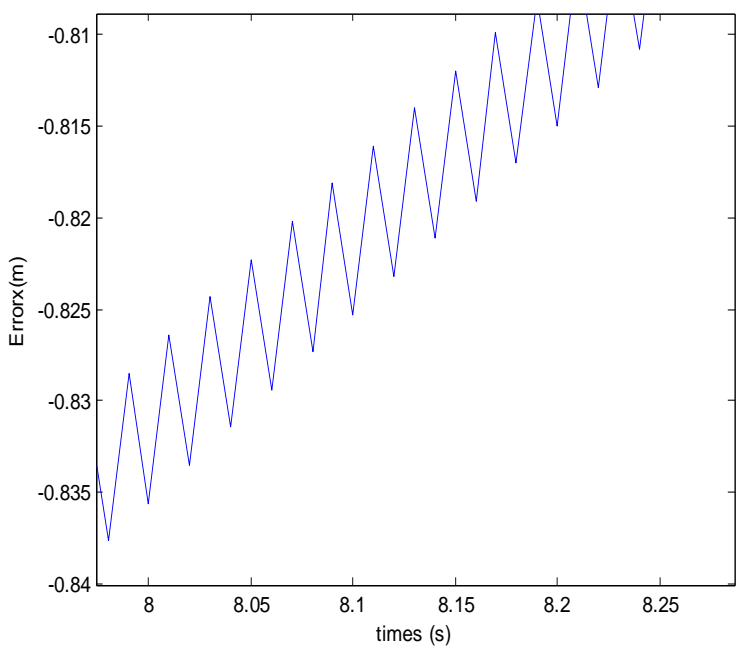

Gambar 8. Chattering pada koordinat X 


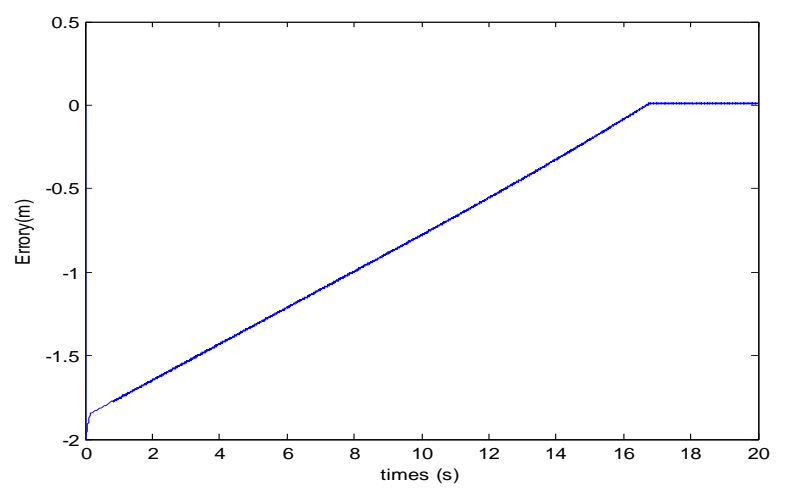

Gambar 9. Tracking Error pada koordinat Y

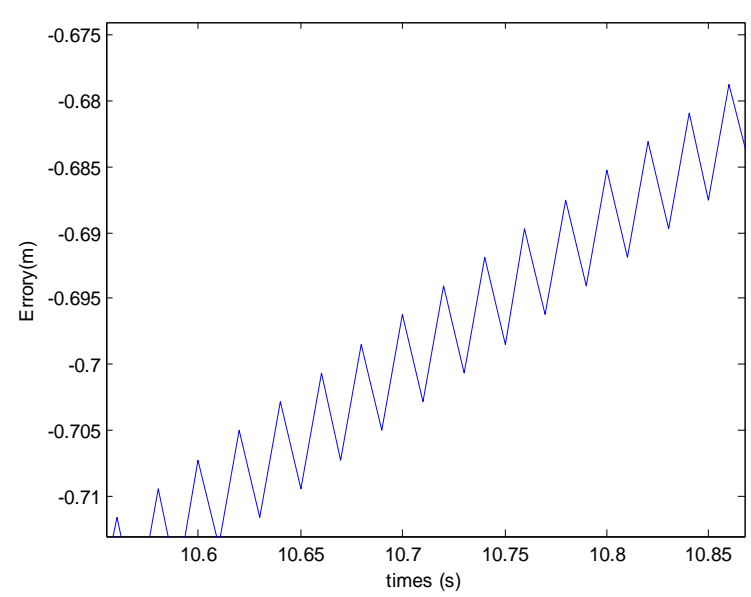

Gambar 10. Chattering pada koordinat $\mathrm{Y}$

Hasil grafik pada gambar 5, menunjukkan bahwa WMR bisa mencapai target dengan respon pergerakan yang baik. Dari gambar tersebut terlihat bahwa keadaan awal WMR pada posisi [qx (0) qy (0) hr (0)] bisa dengan cepat berbalik arah dan mengikuti lintasan yang telah ditentukan. Tracking error koordinat $\mathrm{X}$ dan $\mathrm{Y}$ pada gambar 7 dan 9, terlihat bahwa responnya cepat dalam mencapai posisi stabil dalam waktu 16 detik.

\section{KESIMPULAN DAN SARAN}

Dalam penelitian ini dapat disimpulkan bahwa sliding mode control bisa dijadikan sebagi controller untuk tracking control pada WMR. Selain itu SMC dapat menunjukkan performa respon yang baik dalam memperkecil overshoot yang terjadi saat dilakukan simulasi. Namun $S M C$ mempunyai fenomena chattering yang dapat mengganggu stabilitas dari sistem kendali.

\section{DAFTAR PUSTAKA}

[1] R. Supriyanto Hustinawati, R. W. Nugraini, A. Bima Kurniawan, Y. Permadi, SKom, dan A. Sa'ad, 2010, Robotika. Buku ajar Robotika. Universitas Gunadarma.

[2] AM. Bloch, M. Reyhanoglu, H. McClamorch, 1992. Control and stabilization of nonholonomic dynamic systems. IEEE Tran. On Automatic Control, pp. 17461757.

[3] A Bloch and S. Drakunov, 1994. Stabilization of a nonholonomic system via sliding modes. IEEE international conference on Decision Control, pp. 29612963.

[4] C. Dongkyoung, S. Jin, K. Pyojae and Young, 1999. Sliding mode control for trajectory tracking of nonholonomic wheeled mobile robots. IEEE Transactions of Robotic and Automation, 578-587.

[5] L. Gracia, J. Tornero, 2008. Kinematic Control of Wheeled Mobile Robots. Latin American Applied Research, 38:7-16.

[6] S. Noor Asyikin, 2007. Control Of A On-Holonomic Mobile Robot. fulfilment of the Requirements for the award of the degree of Master of Electrical Mechatronics and Automatic Control) Engineering,

[7] C. Yeong-Hwa, C. Chia-Wen, C. Chun-lin, T. Chin-Wang, 2012. Fuzzy Sliding-Mode Formation Control for Multirobot Systems: Design and Implementation. IEEE Transaction on System, Vol. 42, No. 2.

[8]S. Ryan, 2013. Rancang Bangun Robot Boat Navigasi Tanpa Awak, Skripsi Universitas Sam Ratulangi.

[9]F. Zulhar, M. A. Riyadi, dan I. Setiawan, 2017. Perancangan Sistem Sliding Mode Control Untuk Jarak Elektroda Pada Electrical Discharge Machining. TRANSIENT, Vol.6, No. 1.

[10]M. Utoro, dan J. Pramudijanto, 2014. Perancangan dan Implementasi Kontroler Sliding Mode Pada Pengaturan Kecepatan Motor Induksi Tiga Fasa. JURNAL TEKNIK POMITS, Vol. 3, No. 1.

[11]Slotine, Jean-Jacques E. and Li, Weiping. Applied Nonlinear Control. Prentice Hall International Inc. 1991. 